Article

\title{
Preferences in Between: Moderates in the Catalan Secessionist Conflict
}

\author{
Laia Balcells ${ }^{1, *}$ and Alexander Kuo ${ }^{2,3}$ \\ ${ }^{1}$ Government Department, Georgetown University, USA; E-Mail: laia.balcells@georgetown.edu \\ 2 Department of Politics and International Relations, University of Oxford, UK; E-Mail: alexander.kuo@politics.ox.ac.uk \\ ${ }^{3}$ Christ Church, University of Oxford, UK \\ * Corresponding author
}

Submitted: 29 May 2021 | Accepted: 11 August 2021 | Published: 10 December 2021

\begin{abstract}
Recent research on territorial preferences focuses on explaining who supports or opposes independence. However, this research overlooks the relevance of an "intermediate" category of citizens who may oppose the territorial status quo of a sub-state territory but not support independence. We use evidence from the critical case of Catalonia to illustrate the relevance of individuals with such preferences for policies and outcomes highly relevant to secessionist conflicts. We present four sets of findings using two-wave panel data from December 2017 (just prior to the December regional elections when Catalan independence was the most salient and contentious issue) and September 2018. First, we find that a sizable plurality within Catalonia supports greater autonomy short of independence; conventional sociodemographic variables explaining support for independence do not strongly account for this preference. Second, such pro-autonomy individuals have considerably more intermediate attitudes regarding the key "on the ground" actions that the Spanish and Catalan governments pursued during the crucial independence drive in 2017. They were more opposed than pro-independence individuals to the unilateral independence efforts, and more opposed than pro-status quo individuals to the Spanish government's actions to counter these efforts. Third, they expressed emotions around the secessionist conflict similar to pro-status quo individuals. Finally, using an embedded survey experiment, we find that pro-autonomy individuals are more trusting of both the central and regional governments regarding their abiding by an agreement to resolve the conflict, and are less easily "polarized" through priming. Overall, these findings indicate the importance of further analyzing individuals with intermediate territorial views in secessionist conflicts.
\end{abstract}

\section{Keywords}

autonomy; Catalonia; federalism; secession; Spain; territorial conflict

\section{Issue}

This article is part of the issue "Secessionism in Liberal Democracies: What Do We Really Know About the Explanations of Secessionism?" edited by Ferran Requejo (Pompeu Fabra University, Spain) and Marc Sanjaume-Calvet (Pompeu Fabra University, Spain / Open University of Catalonia, Spain).

(C) 2021 by the authors; licensee Cogitatio (Lisbon, Portugal). This article is licensed under a Creative Commons Attribution 4.0 International License (CC BY).

\section{Introduction}

The recent study of territorial preferences in secessionist regions has primarily focused on explaining who supports or opposes independence. This is understandable due to the increasing salience of secessionist movements, as in Catalonia and Scotland. However, there is often a category of citizens who oppose the territorial status quo of a sub-state territory, but do not support secession (i.e., they support more autonomy for the region, but not independence). Although this "pro-autonomy" category is overlooked in the scholarly literature, it can be key to the political dynamics of the region, such as by withholding support of secessionist political parties. Further, territorial "moderates" can have a role in mitigating social polarization surfacing during secessionist crises. Such individuals often constitute a non-negligible share of the population even when self-determination issues are politically salient; in Scotland, for example, recent surveys show that over 
$40 \%$ of the population would want "increased powers for the Scottish parliament" but not independence (YouGov, 2021).

This article presents evidence from the critical case of Catalonia to illustrate the relevance of individuals who have intermediate territorial preferences (i.e., between the status quo and secession), which we classify as generally pro-autonomy. What are the political implications of these preferences in terms of resolving secessionist disputes? As relatively few studies of this preference exist (particularly from recent years), our goal is to present baseline theoretical expectations and instructive empirical patterns. We examine sociodemographic correlates of this preference and analyze how it correlates with support for policies and attitudes relevant to secessionist conflicts. We also explore whether such individuals differ in terms of their emotional reactions to the secession issue. Finally, we assess whether pro-autonomy individuals differ in their trust of both regional and central governments in a hypothetical territorial agreement scenario, which would be a key component in long-term resolution of the conflict.

We find that that the most relevant distinguishing feature of pro-autonomy individuals is that they self-report moderate levels of Catalan identity and are slightly more likely to be older and female; few other conventional sociodemographic characteristics distinguish them from those who support the territorial status quo or less autonomy for Catalonia (hereafter labeled "SQ \& less autonomy"). Such pro-autonomy individuals tend to agree with pro-SQ \& less autonomy individuals on opposition to actions the Catalan government took, and had similar emotions regarding the political context, but they also show more moderate sentiments than those in the two territorial extremes. Also, pro-autonomy individuals oppose more firmly the repressive actions of the Spanish government towards the pro-independence movement than pro-SQ \& less autonomy individuals. Finally, pro-autonomy individuals display similar levels of trust towards both the Spanish and Catalan governments and are the least susceptible to trust priming, as captured by an experiment embedded in our survey.

\subsection{Literature Review and Motivation}

Our study is motivated by the recent proliferation of literature focusing on the individual-level correlates or determinants of support for secession within democratic countries, but that generally examine binary policy preferences (see, e.g., Bourne, 2014; Hierro \& Queralt, 2021; Muñoz \& Tormos, 2015; Serrano, 2013). This literature, in unpacking group-level claims and focusing on individual preferences, challenges and builds upon classic works focusing on support for secession based on grouplevel sub-state identities, which tended to downplay the nuances of individual territorial preference in favor of a group-level analysis (see Horowitz, 1981, and his typography regarding ethnic separatism; for typologies of political struggles of nations see Guibernau, 1999; Hechter, 2000).

Such recent explanations for secessionist preferences largely fall into two main categories: identity (ethnno-cultural, religion) and material-based (often described as economic benefits or elided as "rationalist" explanations). For example, Balcells et al. (2015) consider regional redistributive preferences and their impact on support for independence in Catalonia. Some authors note the difficulty in differentiating the causal role of these factors, and that they can be mutually reinforcing. For example, Sorens (2008), after differentiating between secessionist and regionalist parties, finds that secession is more tied to economic interests, whereas regionalism is more tied to cultural and identity-based interests. Several recent studies have focused on the confluence of economic and ethnic factors in accounting for individual-level preferences for secession in select regions. For example, Curtice (2013) uses survey data among Scottish/British citizens to argue that nationality (or identity) has much less to do with support for independence than material (economic) factors. Similarly, Muñoz and Tormos (2015) find that economic considerations are an important driver of territorial preferences in Catalonia. However, they note the importance of looking at variation in reasons for pro-independence views and find that economic considerations mostly matter when people do not have a strong national identity. Ormston (2014) meanwhile finds that women tend to support independence less than men, due to their uncertainty of what benefits independence would yield.

Few studies discuss the viability of an "intermediate" category of citizens, or consider the "in between" group as a meaningful unit of analysis. One older exception is Guibernau (2006), who presents descriptive data regarding support for various forms of federalism or territorial reforms in Canada, Spain, and Britain from the late 1990s and 2000s. However, that study considers a period in which secessionism in the two European countries was much less salient in the political arena and does not focus on the correlates and implications of these territorial preferences. We also note a tradition of studying support for the devolution process in Scotland in the early 1990s (e.g., Pattie et al., 1999), as well as research on decentralization preferences in other contexts. For example, Ricart-Huguet and Green (2018) find that ethnic identity and wealth are correlated with preferences for greater regional decentralization in Uganda.

Overall, neglecting those with "intermediate" preferences is significant, not only because such individuals constitute an important segment of the population, but also because such preferences can have key political implications. As Guibernau (1999) and others have noted, although a vocal fraction of stateless nations seek independence, increased autonomy within existing institutions has frequently been proposed as a long-term solution, even though such reforms' empirical record at reducing independence demands remains mixed and 
contentious. Our broad point is that in cases where secessionism is salient, those who are against the status quo but are not in favor of secession merit greater understanding. Such individuals might change their territorial preferences in either direction, which makes them pivotal in such political contexts. To this end, we explore the pro-autonomy, "intermediate" category at the height (thus far) of the secessionist conflict in Catalonia, when such an option was less visible and salient than the more extreme territorial positions. Who are the people that, amid the polarizing secessionist conflict, support greater autonomy? What are the implications of the existence of this differentiated group?

\section{The Case of Contemporary Catalonia}

Contemporary Catalan nationalism has its roots in the 19th century (Balcells, 2013). In the 1930s, Catalonia achieved autonomy within Spain, with a regional parliament and a government, among other institutions of self-rule. However, during the Francoist dictatorship that followed the Spanish Civil War (1936-1939), cultural rights for national minorities in Spain (i.e., Basques, Galicians, Catalans) were repressed, and Spanish nationalism was imposed by state institutions (Balcells \& Villamil, 2020). Since the transition to democracy after 1975 , national minorities regained some level of self-rule in a decentralized system that fell short of full federalism (Beramendi, 2012). The process of decentralization was uneven among national minorities, with the Basque country and Navarra regions attaining fiscal privileges not afforded to the other regions. This differential lack of fiscal autonomy, grievances over regional redistribution, and desire for increased political autonomy, combined with commitment problems between the center and the periphery (Amat \& Balcells, 2021; Requejo et al., 2020), have historically spurred tensions between Catalonia and Madrid.

In 2010, after a long set of negotiations that culminated in central and Catalan government approval of a new Catalan statute of autonomy (a regional constitution), the Spanish Constitutional Court revised and interpreted the statute in a manner that significantly weakened the region's autonomy. Support for independence then increased from a previous level of $15 \%$ in 2006 to around $45-50 \%$ in 2012 (Centre d'Estudis d'Opinió [CEO], 2021). Support for more autonomy was a prevalent choice in Catalonia until around 2010, when support for independence grew at the expense of this middle category. Political support for separatism further increased in 2015, when the Catalan premier Artur Mas called for a snap election around the independence issue. The Together for Yes (Junts pel Sí) coalition won a majority of the seats in the Catalan Parliament (71 seats; $44.4 \%$ of the popular vote) with a program to implement independence within 18 months. Carles Puigdemont, the new Catalan premier, then called for a unilateral referendum on independence. The referendum was sched- uled for October 1, 2017, and controversially approved by a set of laws passed in the Catalan Parliament (38\% of MPs did not participate and an additional $8 \%$ abstained in the vote).

In the weeks prior to the referendum, the political climate became increasingly heated as the Catalan government continued its preparations while the Spanish government tried to prevent it, including detaining several members of the Catalan government who were allegedly involved in its organization. The Spanish government sent thousands of national policemen to Catalonia to deter and prevent voters and activists from organizing (Barceló, 2018). Despite the Spanish Constitutional Court suspension of the referendum laws and central government threats about legal consequences, the Catalan government proceeded with the referendum on October 1. This led to an unprecedented crackdown by Spanish police forces as they attempted to shut down polling stations (Balcells, Dorsey et al., 2021). On October 3, the King of Spain delivered a controversial speech against Catalan separatists and there was a labor strike and large demonstration in Barcelona against the actions of the state. A few days later, there was a counterrally against the independence process and the actions of the Catalan government. The crisis continued with the Catalan Parliament passing a resolution declaring Catalonia independent of Spain on October 27 (although with no operational effects), and the Spanish Senate quickly voting for the temporary suspension of Catalan autonomy, activating for the first time a constitutional clause (article 155) allowing the central government to impose direct rule in a region. This led to the dissolution of the Catalan government, and the central government called for new regional elections, which were held on December 21, 2017.

Meanwhile, the Spanish judiciary began the prosecution of prominent secessionist leaders, including social activists Jordi Cuixart and Jordi Sànchez, who were jailed under charges of sedition for attempting to block police raids on Catalan governmental offices. Members of the former Catalan government and the High Chair of the Parliament were charged with sedition and rebellion. Some fled the country; those who stayed in Spain were imprisoned and were later brought to trial in the Supreme Court of Spain.

In the December 2017 regional elections, the three main pro-independence parties secured another parliamentary majority (with $48.5 \%$ of the vote), then led by Quim Torra. In June 2018, socialist leader Pedro Sánchez won a motion of no-confidence in the Spanish Congress and became President, replacing conservative Mariano Rajoy. Although this led to some prospects of negotiations between the central government and the Catalan government, the stalemate persisted. In October 2019, after the sentencing by the Supreme Court of the imprisoned politicians and social organizers to 9-13 years of prison on charges of sedition, mass demonstrations and violent protests occurred throughout Catalonia. In June 
2021 the central government officially pardoned the nine Catalan separatist leaders who were jailed and negotiations between the Spanish and Catalan government resumed shortly after.

\section{Expectations}

In the context of a secessionist conflict, who are the individuals supporting intermediate options such as federalism or more autonomy for the region, but neither outright secession nor maintaining the territorial status quo? Building on documented correlations between substate identity and secession support (Hierro \& Queralt, 2021; Muñoz \& Tormos, 2015; Serrano, 2013), we first expect a correlation between individuals who have moderate levels of sub-state national self-identification (in this case, Catalan as opposed to Spanish) and likelihood of preferring a "greater autonomy" option relative to independence or the status quo. Similarly, a reasonable expectation is that individuals who are in a mixed-language (Catalan and Spanish) household are more likely to support greater autonomy relative to the two other options. We further expect that pro-autonomy individuals might be less supportive of actions by either central or regional governments that are perceived to be illegal or extreme. That is, such individuals may be oriented towards "process" concerns as a component of policy preferences (for them, how to achieve a goal may be as important as the goal itself).

\section{Empirical Design}

Catalonia is a natural and important testing ground for measuring how much people support an intermediate territorial outcome in the context of a secessionist conflict, and what are the implications of such intermediate preferences. To examine these issues, we designed a survey, which we fielded online between December 11 and 20, just prior to the 2017 regional elections. Our representative sample consisted of 2,537 residents of Catalonia aged 18 or older, fulfilling age-category and gender quotas. The survey was fielded by Respondi in Catalan or Spanish (respondents chose their preferred language at the beginning of the survey). To test the stability of preferences after the elections and after the re-imprisonment of several independentist leaders, we fielded a follow-up survey between September 19-30, 2018; 63\% respondents were re-interviewed in the second wave (we registered two pre-analysis plans with EGAP prior to receipt of data, and the study received IRB approval from Georgetown University and the University of Oxford). Tables A1 and A2 in the Supplementary File provide basic descriptive statistics of the sample, including territorial preferences, language spoken at home, family origins, education, income, and gender. The composition is representative of the regional population, very similar to the samples used by the CEO, with a slight skew of younger respondents across waves (our results remain substantively very similar when estimated with weights by age and gender).

Our main variable of interest is territorial preference, with attention to support for the intermediate category of greater autonomy. We measure territorial preferences by asking individuals for their preferred political status of Catalonia. Following standard survey questions on this issue (i.e., those by the CEO), the response options were: They prefer Catalonia to be an independent state (we will also call this option "Catalan Republic"); Catalonia should have more autonomy but not independence (we will also call this option "more autonomy"); the status quo should be kept; Catalonia should have less autonomy. For our analyses below, we recode to consider three broad categories: "Catalan Republic," "more autonomy," and "SQ \& less autonomy." The Supplementary File (Part B) includes coding details of the control variables, and Tables A1 and A2 display the descriptive statistics of all our data.

The bulk of our empirical results focus on the first wave of the survey; we present selected results from the second wave here and more in the Supplementary File. The second wave patterns are very similar to the first, indicating a remarkable stability of preferences over time (see Table A3 in the Supplementary File). In addition to the observational analyses, which focus on the correlates of the intermediate territorial preference (i.e., more autonomy) and on the implications of such preferencefor example, for political choice (i.e., vote), views on governmental actions, and emotions-we also present the results of an embedded experiment (within the second wave of the survey) that assesses relative trust of the Catalan versus Spanish governments with regards to their abiding by a hypothetical center-region political agreement.

\section{Results}

\subsection{Correlates of "More Autonomy" Support}

In the first wave of the survey ( $N=2,537), 44 \%$ of respondents prefer a separate Catalan state, $35 \%$ want more autonomy, $20 \%$ support the SQ \& less autonomy. In the second wave $(N=1,721)$, the patterns are very similar, with slightly more supporting independence (nearly $47 \%), 33 \%$ supporting more autonomy, and $21 \%$ supporting the SQ \& less autonomy (see Table A3 of the Supplementary File).

Which variables are correlated with support for greater autonomy? One interpretation of territorial preferences is that they constitute a natural "ordering" from greatest autonomy (independence) to least (the status quo), but we avoid estimating an ordinal logit regression as the baseline specification after conducting a Brant (1990) test and ascertaining that the proportional odds or parallel regression assumption is violated. We estimate a multinomial logit regression model, and focus on the following independent variables: female gender, education, age, adjusted income, left-right ideology, 
primary language spoken at home, and national selfidentification or Catalan identity (see coding details in the Supplementary File, Part B). In alternative models (Supplementary File, Table C1 and Figure D2), we also assess the effect of family origins (a variable basically capturing if the respondent and their parents were born in Catalonia or not). Figure 1 displays the plotted marginal effects of the sociodemographic variables on each of the three territorial preference categories, using the first wave of the survey (note that the results of the second wave are very similar; see Supplementary File, Figure D1). Although our focus is on "more autonomy" (the middle panel), we find it instructive to compare the relative marginal effect of covariates on all three territorial preferences. All figures should be interpreted such that if the plotted coefficient's confidence interval overlaps with the vertical line there is not a precisely estimated effect relative to the baseline level of the variable. Each of the plotted predicted effects can be interpreted in percentage points: For example, the upper right figure indicates that those with high levels of Catalan self-identification are nearly 80 percentage points more likely to support independence relative to the baseline category, which are those with lowest levels of Catalan identity.

Figure 1 does not indicate support for our hypothesis regarding the role of language but does confirm the expectation regarding identity. For the language categories, relative to the "Spanish language only" group, both "mixed language" and "only Catalan language" individuals are less likely to be more pro-autonomy; the latter are much less likely to be pro-autonomy than the other two language categories because they are more strongly pro-independence (people who speak only Catalan are 20 percentage points more likely to support a Catalan republic). The top two lines of the figure indicate stronger support for the role of Catalan (vs. Spanish) national identity in accounting for moderate territorial preferences.To measure national identity we use the following question: "Could you describe on the scale if you feel very Spanish or very Catalan, with 1 indicating you feel only Spanish and 10 indicating you feel only Catalan?" We recode the answers as approximate "terciles" of 1-4, 5-7, 8-10. The figure shows a strong correlation between identity terciles and territorial views. The middle tercile is most strongly correlated with support for autonomy and more so than with independence. The effect is large, 30 percentage points relative to the lowest tercile. The highest tercile of Catalan identity is negatively correlated with support for autonomy, as such individuals overwhelmingly prefer independence. While we are not claiming a causal relationship, we highlight this intermediate identity as a relevant variable that political elites seek to influence (Hierro \& Gallego, 2018) and that is strongly correlated with the pro-autonomy policy preference.

In the first wave of the survey, we also posed a follow-up question about the reasons for autonomy, focusing on the distinction between fiscal autonomy and policy control. For pro-autonomy individuals, respondents chose between two options: "Greater autonomy for Catalonia should imply, most importantly, greater autonomy over the use of Catalan fiscal resources," and "Greater autonomy for Catalonia should imply, most importantly, more control of public policies by the Catalan institutions, with less interference from the central state." Sixty percent chose the "fiscal resources" option, and the rest chose "more control of public policies." The only statistically significant (and positive) covariates for the fiscal resources (vs. public policies) choice are (right-wing) ideology, the wealthiest income quintile, and the third age group (45-54). See Supplementary File Table F1 for regression results.

Figure 1 indicates that female gender is positively correlated with support for autonomy, although the marginal effect is small at around 5 percentage points. The figure also shows that education, unemployment, and income levels surprisingly do not differentiate territorial preferences. Older individuals $(45+)$ are more likely

Marginal Effects (with 95\% Cls) for Multinomial Logit
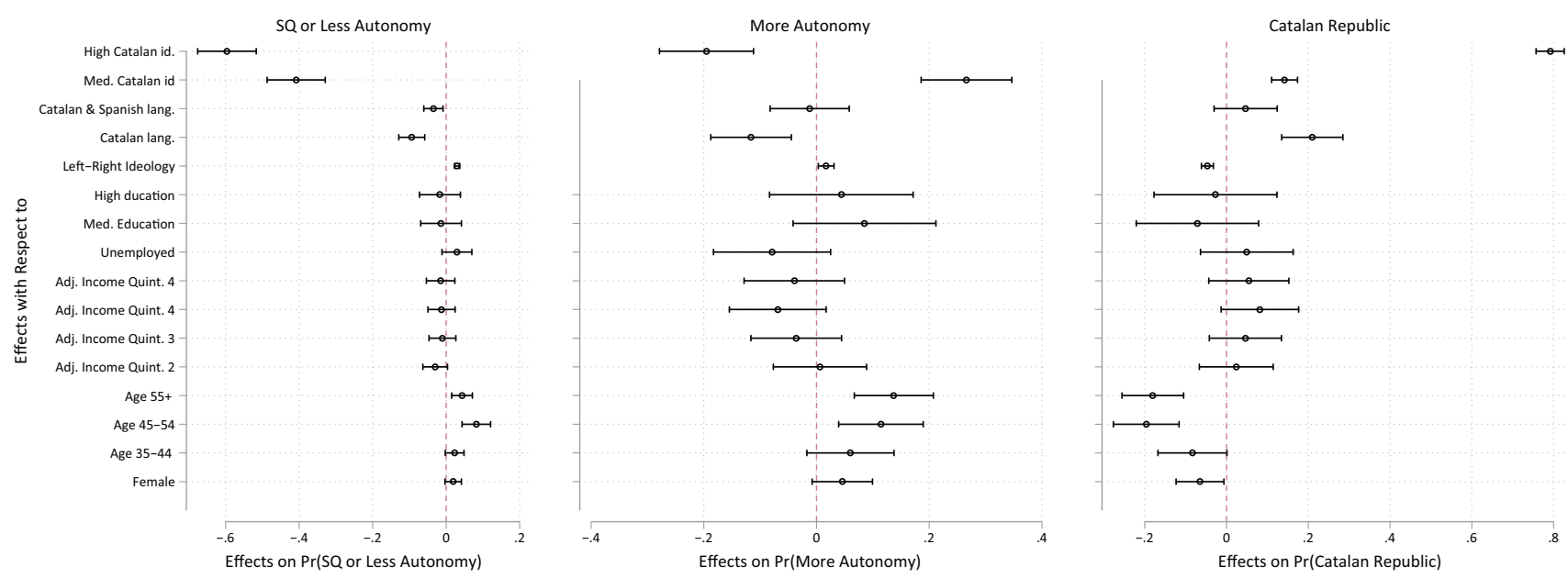

Figure 1. Correlates of territorial preferences: Multinomial logistic regression marginal effects (wave 1). 
to support autonomy relative to the other two territorial positions. Ideology is also correlated with these preferences; more right-wing individuals are more likely to favor SQ \& less autonomy and more autonomy, while more left-wing individuals are more likely to display proindependence preferences. Catalan speaking individuals and those with greater levels of Catalan national identity are less likely to support autonomy (again, they are more likely to support independence).

\subsection{Territorial Preferences and Key Policy Views}

Is the preference for greater autonomy (but not independence), particularly during a secessionist escalation, a meaningful one that correlates with obvious "on the ground" government actions? As a partial validation exercise of this preference, in the survey we measured support of a series of salient actions by both the Spanish and Catalan governments during the contentious period of the referendum and the repressive response by the Spanish government, which we have summarized above. We assessed support on a five-point scale for the following government actions (see full wording in Supplementary File, Part B): the unilateral independence referendum of October 1 , the actions of the Spanish government on October 1 , the declaration of independence by the Catalan government on October 27, the arrest of the two prominent Catalan pro-independence civil-society leaders (Jordi Cuixart and Jordi Sànchez, or "Jordis"), the arrest of Catalan politicians who led the independence effort (i.e., the members of the Catalan government at that time), and the passage of article 155 (which imposed direct Spanish government control over the region). While there were other actions by both the Spanish state and the Catalan government during this crucial time, this group of policies constitutes a reasonable summary of the actions of both actors prior to the centrally imposed December 2017 regional election.

Figure 2 shows via "violin" plots the decomposition of support or opposition for the central and regional governments' actions based on the three territorial prefer- ences (these variables capture, on a 1 to 5 scale, the degree of support for the policy). The plots in Figure 2 show very clearly that, for the six policies, pro-autonomy individuals have levels of support largely in between those who prefer the territorial SQ \& less autonomy and those who prefer independence, and thus more moderate degrees of support/opposition. If we consider binary support for each of these actions (see Supplementary File, Tables E1 and E2), 39\% of the pro-autonomy group supports the October 1 referendum compared to $94 \%$ among pro-independence and $6 \%$ among pro-status quo individuals. Also, $82 \%$ of pro-autonomy individuals oppose the actions of the Spanish government on October 1, compared to $98 \%$ of pro-independence individuals. Interestingly, pro-autonomy people are more supportive of the referendum than of the Catalan parliament's declaration of independence, which was politically linked to the referendum. Only $9 \%$ of pro-autonomy individuals supported the independence declaration, as opposed to $79 \%$ of pro-independence individuals. Indeed, many pro-autonomy people perceived the referendum a legitimate act of self-determination, but did not perceive the declaration of independence as such. This is suggestive evidence that pro-autonomy individuals are more averse to actions and policies that are more extreme.

Figure 3 shows that this pro-autonomy pattern of support/opposition falling in between that of pro-status quo and pro-independence individuals generally holds when controlling for sociodemographic variables. The figure shows, for each of the six government actions, the plotted coefficients from a linear model with the territorial positions and sociodemographic controls. The baseline policy preference is support for independence, so plotted coefficients in either direction of the vertical line indicate greater support or opposition relative to proindependence individuals. The figure shows that overall, territorial preferences are the most important correlate of views towards these specific government actions. Also, for each government action, the coefficient of proautonomy is generally smaller than the pro-SQ coefficient. Figure 3 shows that pro-autonomy individuals are
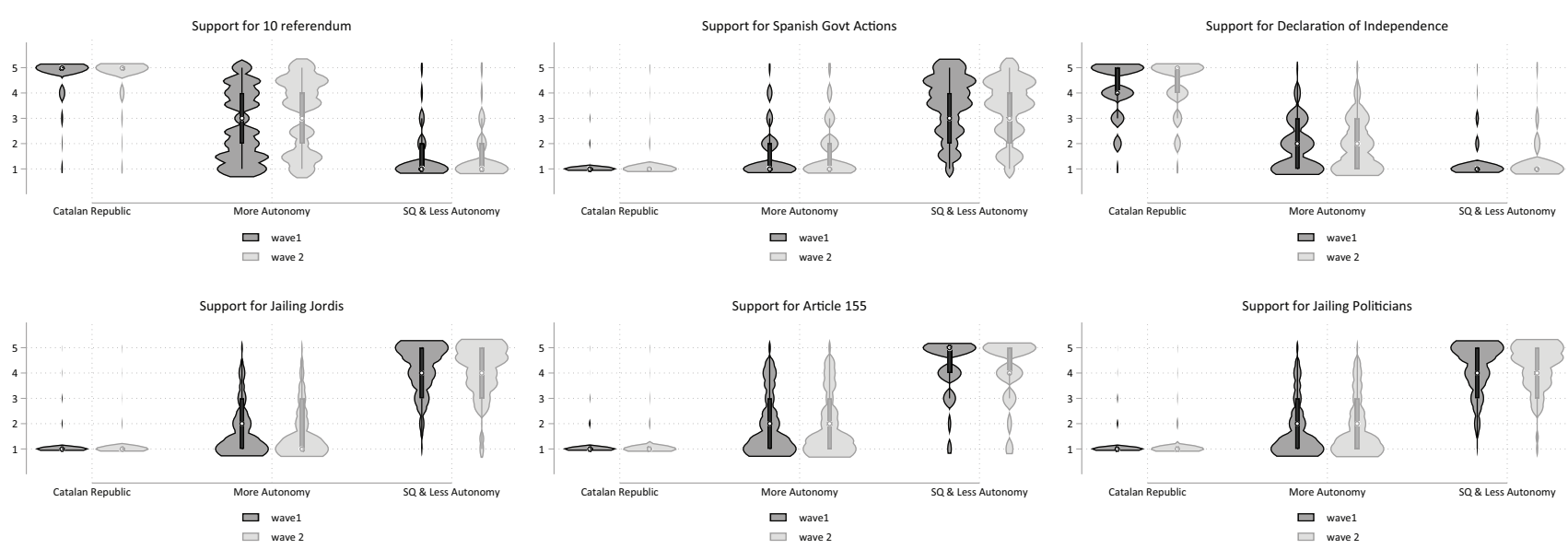

Figure 2. Views on policies by the Spanish state and the Catalan government, by territorial preference (waves 1 and 2 ). 


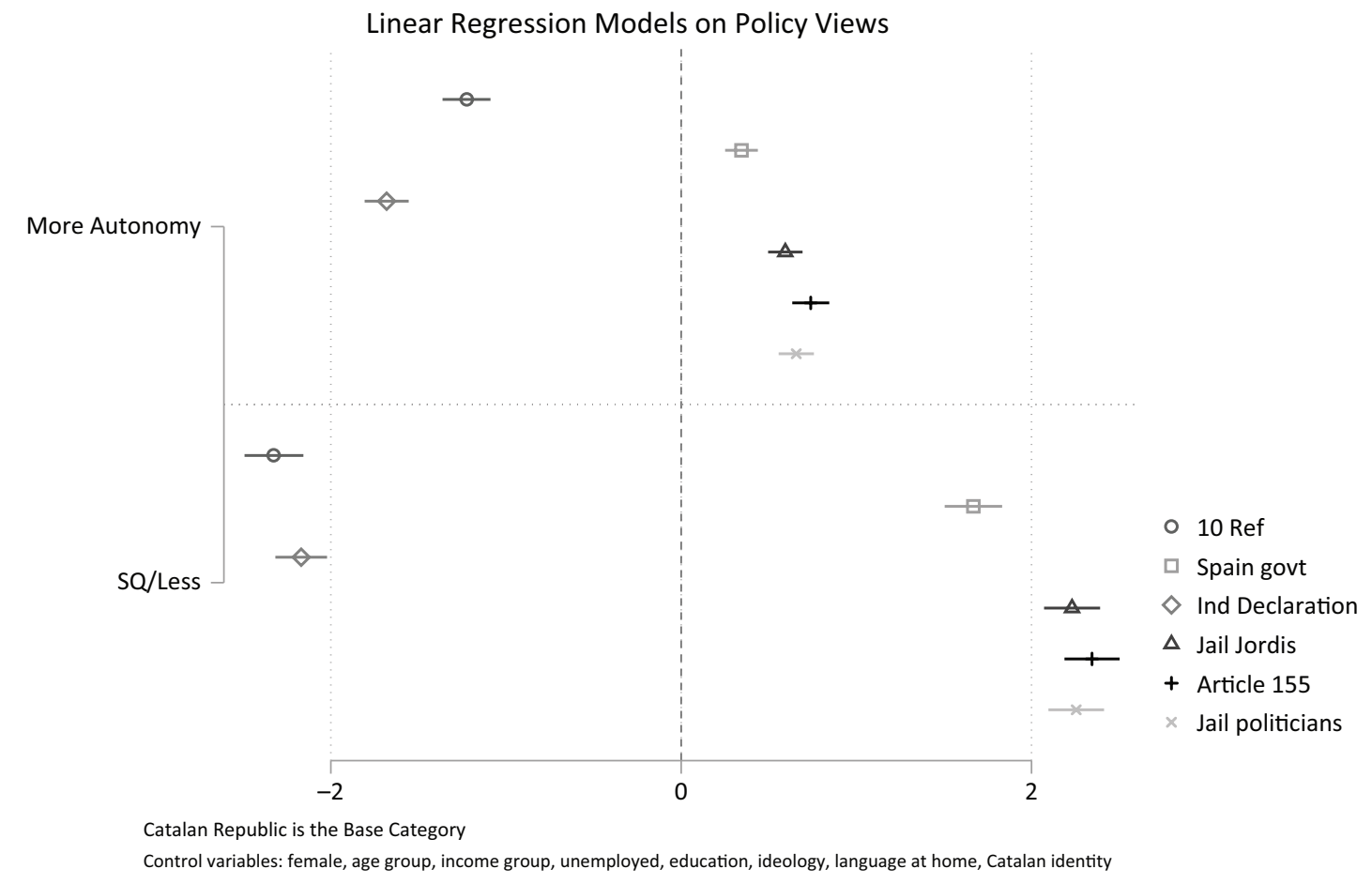

Figure 3. OLS regressions on support for government actions by territorial preferences (wave 1).

closer to pro-independence individuals regarding opposition to the Spanish government's actions (i.e., repressing the vote on October 1 , imprisoning social activists and members of the Catalan government, and activating article 155 of the Constitution). At the same time, pro-autonomy individuals are closer to pro-SQ individuals in terms of their opposition to the referendum and the independence declaration by the Catalan parliament. The results in Figures 2 and 3 potentially suggest a difference between views about "process" versus "outcome": While pro-autonomy individuals share some goals with pro-SQ \& less autonomy as well as with proindependence individuals, they have a different vision of how to achieve these goals. With regards to achieving greater self-government for Catalonia, they indicate greater valuing of the existing rule of law (i.e., in not supporting a unilateral declaration of independence); with regards to defending the unity of the Spanish state, a goal they share with the SQ \& less autonomy individuals, they value proportionate state action (i.e., they are less supportive of jailing social activists and politicians) and do not support extreme measures such as the suspension of Catalonia's autonomy (i.e., article 155) as much.

In the second wave of the survey, we also asked individuals how much they support or oppose the leaders of the central and regional governments, Pedro Sánchez and Quim Torra, respectively. These results (see Supplementary File, Part E) indicate that pro-autonomy individuals show preferences for these politicians that are closer to the SQ \& less autonomy group than to the pro-independence group.

There is also a natural correlation between policy views and partisan preferences. We examine the relationship between territorial preferences and vote choice, measured with a vote-intention question for the December 2017 regional elections (in the first wave) or on hypothetical future regional elections (in the second wave). The results of the linear probability models on vote choice for the main political parties are presented in Figure 4 ( 1 indicates vote intention for that party, 0 not; the results for the second wave are very similar; see Supplementary File, Figure I1). We observe that those with intermediate territorial preferences resemble status quo individuals in that they are less likely to vote for pro-independence parties (Esquerra Republicana de Catalunya [ERC], Junts per Catalunya [JxCat], and Candidatura d'Unitat Popular [CUP]). Unlike the status quo voters, those in the more autonomy category's preferred political party is not Ciudadanos (Cs), but they are more likely to vote for this party than for pro-independence ones. Pro-autonomy individuals are more likely to vote for Partit Socialista de Catalunya (PSC) and En Comú Podem (ECP or Comuns), which have 33 and eight seats, respectively, in the 135 seats of the Catalan parliament (thus, these parties are far from having a majority of the seats, but they hold a non-negligible share of $30 \%)$. As compared to pro-independence voters, they are not more likely to vote for Partido Popular (PP), the main Spanish conservative party (currently holding just three seats in the Catalan parliament).

\subsection{Emotions and Territorial Preferences}

Another key facet by which pro-autonomy individuals might differ from those with other territorial preferences concerns emotions about the political context. 


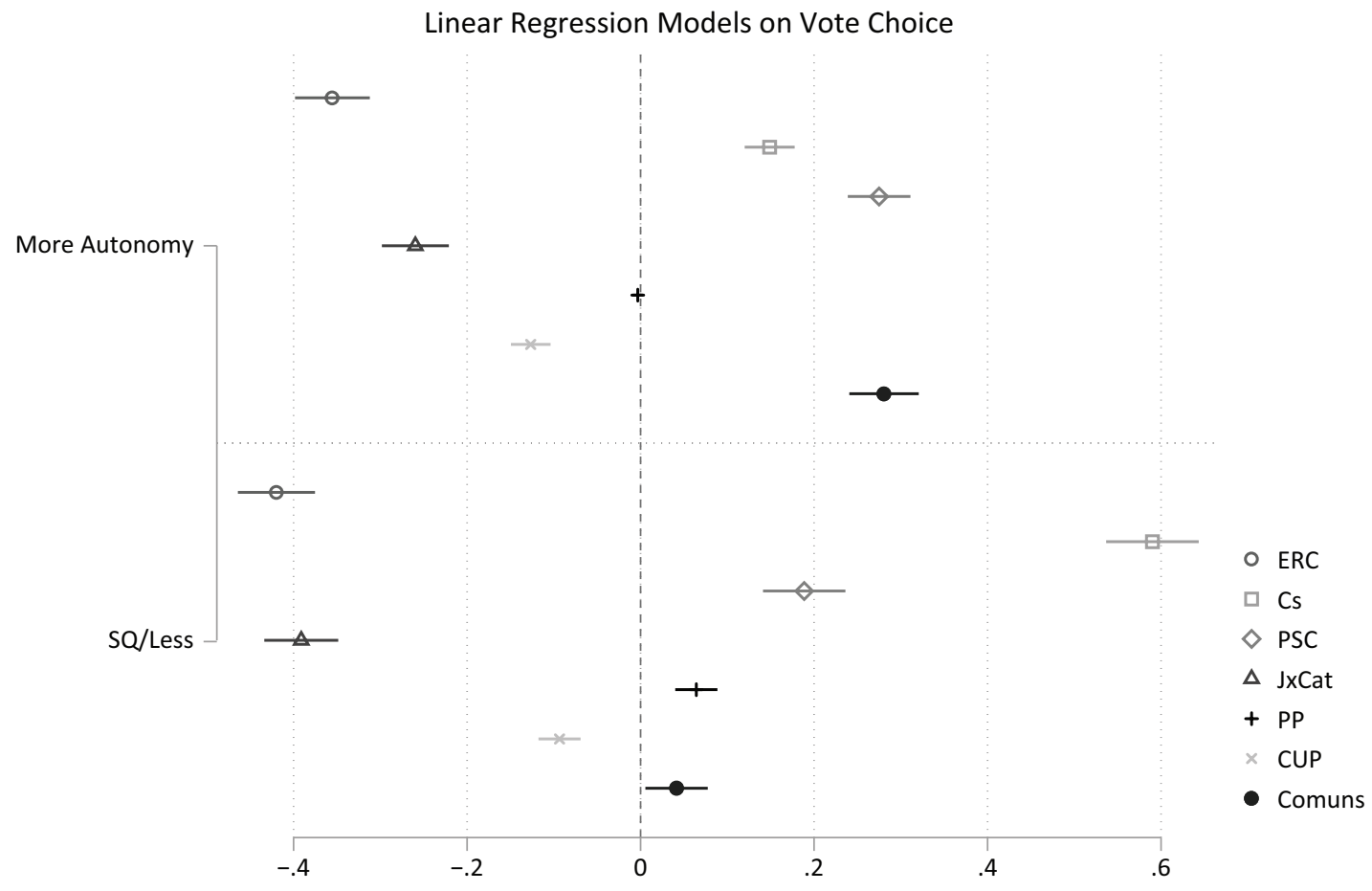

Figure 4. OLS regressions on vote choice by territorial preferences (wave 1).

Such differences are relevant, as political parties or the media may use various frames or campaigns to sway emotions, particularly in the wake of potentially traumatic or salient events such as a unilateral referendum and its crackdown and protests (Balcells, Dorsey et al., 2021). We measured emotions about the political situation in both waves, using standard questions (following Watson \& Clark, 1988) about positive emotions (of feeling determined, enthusiastic, inspired, and proud), and negative emotions (of feeling afraid, ashamed, distressed, irritable, nervous, and upset; see the full wording in the Supplementary File, Part B). We assess on a five-category scale how much the person feels each emotion regarding the political context in Catalonia. In our empirical analyses, we focus on whether the "intermediate" bloc has different emotions from the other two. We find that overall, those supporting more autonomy had similar emotions to pro-SQ \& less autonomy individuals, with those supporting independence having different emotions. Figures 5 and 6 display linear regressions of emotions on territorial preferences, controlling for sociodemographic covariates (Figures A2 and $A 3$ in the Supplementary File depict these patterns with descriptive "violin" plots). These figures show the marginal effects relative to the baseline of pro-independence individuals. Figure 5 shows that, in December 2017, pro-autonomy individuals felt substantially more ashamed and slightly more afraid than proindependence individuals. Moreover, Figure 6 shows that pro-autonomy individuals felt less of all four positive emotions than this baseline group, and that the magnitude of these coefficients is similar in point estimates to
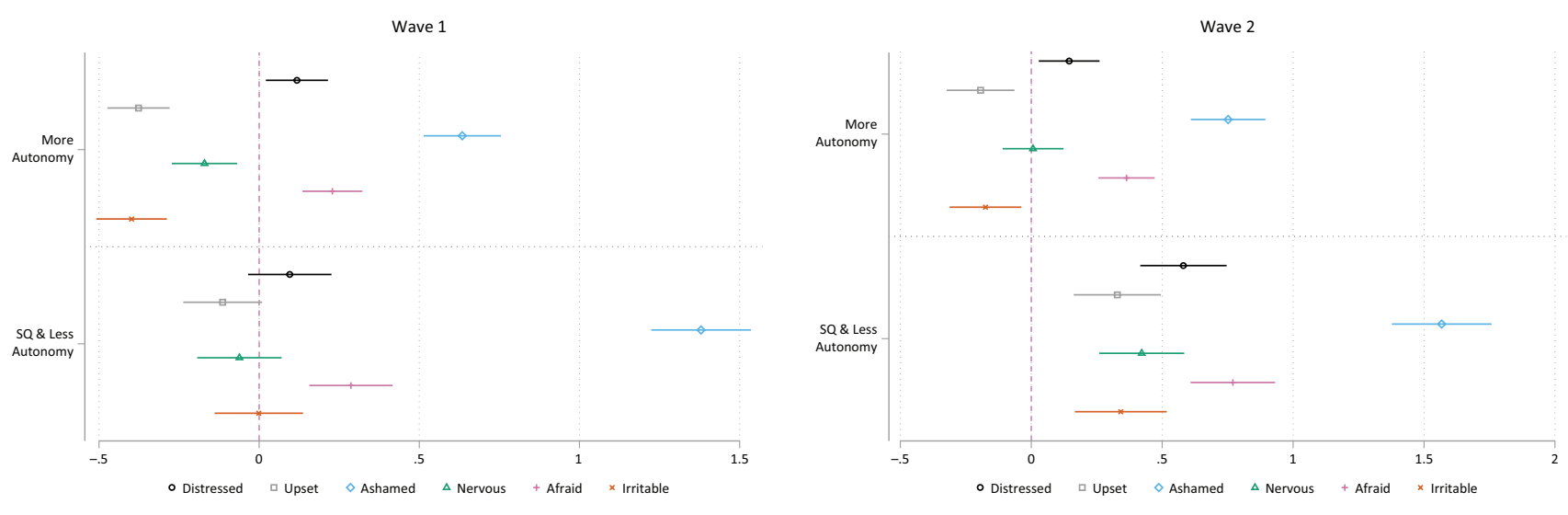

Figure 5. OLS models on negative emotions. Coefficients for territorial preferences. 

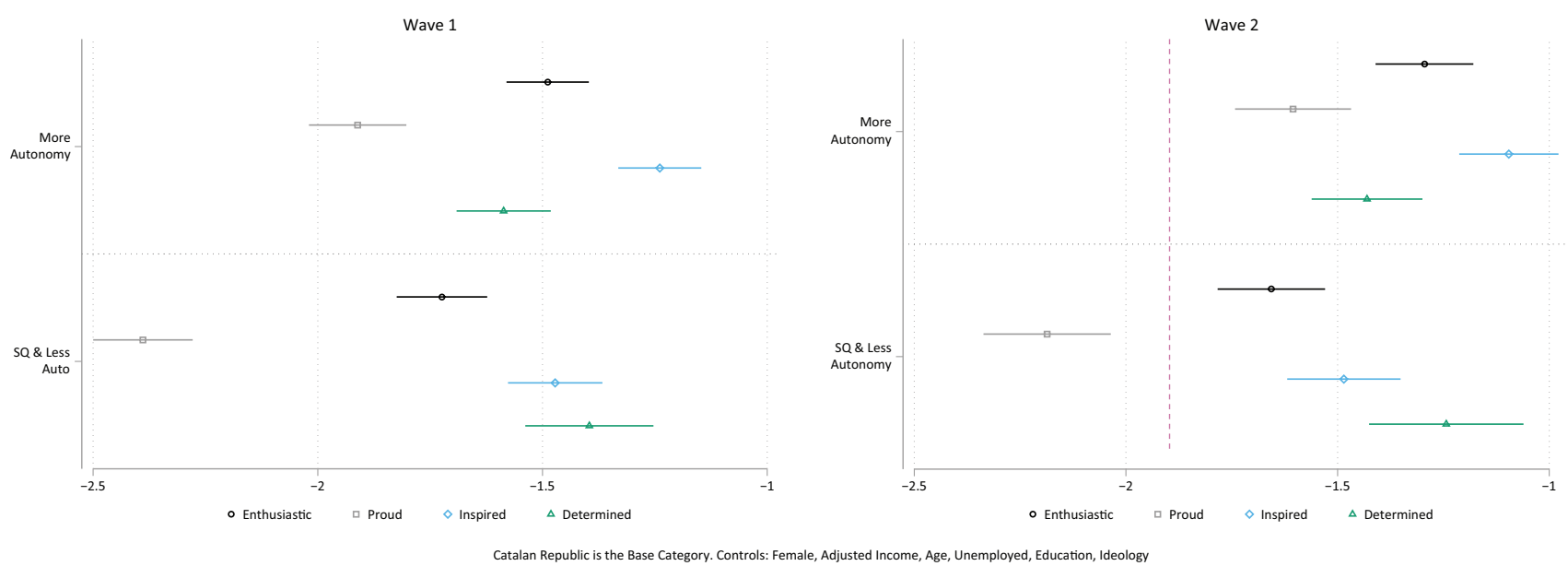

Figure 6. OLS on positive emotions. Coefficients for territorial preferences.

that of pro-SQ individuals. Thus, pro-autonomy Catalans were not particularly positive about the political context in the wake of the independence bid by the Catalan government and its crackdown by the Spanish government.

In the Supplementary File, we present the results of sentiment analyses, using the text in an open-ended question included in each of our surveys, which show that those with intermediate territorial preferences express different sentiments than those in the two extremes. In general, these individuals show more moderate sentiments, for both positive and negative affect. One interpretation of these results is that by having less intense sentiments about the political context, proautonomy individuals might be less susceptible to political entrepreneurs who try to sway emotions.

\subsection{Territorial Preferences and Government Trust: Evidence From a Survey Experiment}

Are pro-autonomy individuals different in how they might trust the regional versus central governments regarding the territorial issue? Is such trust stable? The territorial conflict in Spain is partially defined by commitment problems between the majority group and the minority groups, which are represented by the central government and the different regional governments, particularly those with substate national groups aiming for more self-government (Amat \& Balcells, 2021; Requejo et al., 2020). Given that a possible resolution to the territorial conflict involves an agreement between regional and central governments, ideally solving the commitment problems between them-and quite particularly limiting potential agreement defections, we explore the correlation between territorial preferences and trust in the different governments abiding by the terms of an agreement. In our second survey wave, we examined whether trust in the Catalan versus Spanish governments, in a hypothetical situation of agreement, differs by territorial view. We also assess susceptibility to order effects of being asked about trust in the (Catalan or Spanish) government, which is a simple way of testing whether positive/negative priming of trust in one authority affects trust in the other. Our focus is on whether proautonomy individuals trust both governments more so than other individuals, and if they differ in sensitivity to trust priming.

Figure 7 presents a plot with the relationship between trust in both governments and territorial preferences, which pools the preferences of those in the treatment and control groups. We observe that proautonomy people are those more likely to trust both governments quite similarly, pro-independence people are more trusting of the Catalan government and pro-SQ \& less autonomy people are more trusting of the Spanish government. This relative distrust in the "other" government abiding by a territorial agreement is a good illustration of the commitment problem underlying the territorial conflict(s) in Spain, which seems to be less salient among those with intermediate territorial preferences. Pro-independence individuals show the biggest gap in trust between the two governments.

It is beyond the scope of this study to assess the commitment problem theory or other underpinnings of relative trust in governments abiding territorial agreements. Also, we deliberately do not specify the terms of such an agreement in the survey question; some respondents may conflate trust with support for such an agreement (for example, an agreement encompassing the possibility of a self-determination referendum is different from an agreement without such a provision). Yet, these findings are relevant insofar as they show that there are differences in trust in the different governments across territorial preference groups.

The results of the survey experiment are also quite illustrative of the divergence in trust across groups. As a reminder, the treatment in the embedded experiment was the order in which the government's trustworthiness (Spanish or Catalan) was asked about. This is a standard priming experiment embedded in a survey, where the treatment is reversal of order of a question 

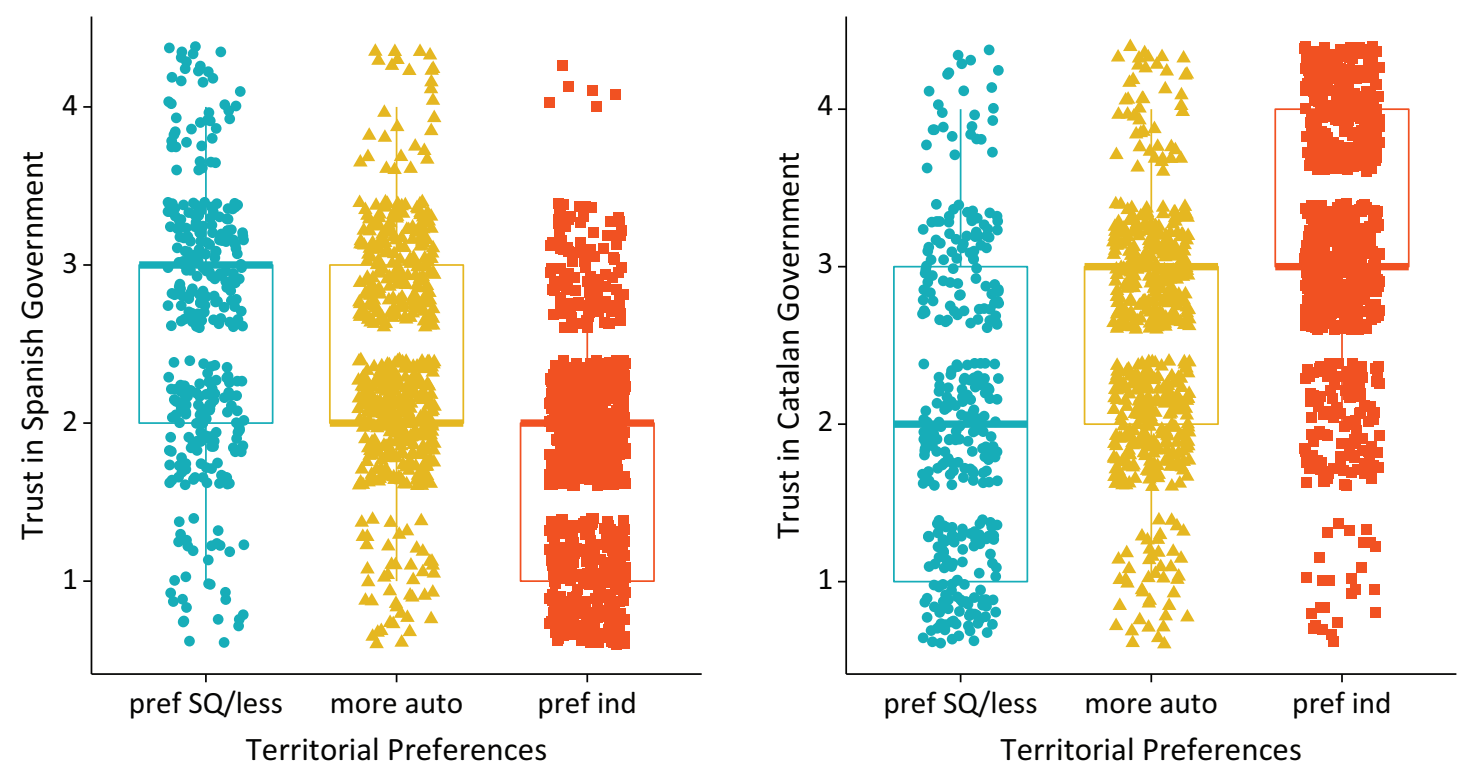

Figure 7. Trust in Catalan and Spanish governments abiding by an agreement, by territorial preferences.

or set of questions (e.g., Sniderman et al., 2004). This allows us to examine whether responses are primed by random assignment of consideration of specific issues (in this case considering trust in the regional government). The text of the question was as follows, with the slash indicating the alternative identity of the government randomized (half the respondents received the Spanish-Catalan order; the other half received the Catalan-Spanish order): "Suppose that the Spanish government and Catalan government were to reach a longlasting agreement about the political future of Catalonia. How much do you trust the [Spanish/Catalan] government to abide by the terms of such an agreement?" The response options were: strongly trust, somewhat trust, somewhat distrust, strongly distrust. The followup question, with the same response options, read: "And how much would you trust the [Catalan/Spanish] government to abide by the terms of such an agreement?"

We label the "control" group as those asked about trust in the Spanish government first, and the "treatment" group as those asked about trust in the Catalan government first. Our main quantities of interest are how relative trust in the different governments under an agreement scenario varies by territorial preference, and whether such preferences moderate susceptibility to order effects. The treatment group in this design is simply whether they are assigned to assess trust in the Catalan government prior to that of the Spanish government (so, again, "treated" respondents are primed to assess trust in the Catalan government first). Interestingly, within the baseline "control" condition, only 35\% strongly trust or somewhat trust the Spanish government to abide by an agreement, while $63 \%$ strongly or somewhat trust the Catalan government to do so.

To account for possible systematic differences in levels of trust, we measure relative trust in the governments: We rescale both trust measures, take the differ- ence, and rescale the trust-difference in a 0-1 scale so that higher values indicate more trust of the Catalan government relative to the Spanish government (a value of .5 indicates equivalent trust of both institutions to abide by an agreement). The average value of this rescaled trust within our artificially labeled "control" condition is .59. Within this group, $53 \%$ have the same level of trust both governments, $40 \%$ trust the Catalan government more so, and $7 \%$ trust the Spanish government more (note, this could mean that a person somewhat distrusts the Spanish government but strongly distrusts the Catalan government). Those who support independence have a relative trust score of .68; those who support autonomy have a trust measure of .51 , and those who support the SQ \& less autonomy have a score of .49. Thus, consistent with Figure 7 , those who are pro-independence are much more trusting of the Catalan government vs. the Spanish government.

We now turn to the effect of the treatment condition (being asked about trust in the Catalan government first). For pro-independence and pro-SQ supporters, asking about the Catalan government first affects trust in expected directions. Pro-independence individuals trust the Catalan government more in the treatment versus the control condition (.76 vs. .68, $p<.001)$. Moreover, pro-SQ individuals' relative trust in the Spanish government is higher in the treatment condition (.33 vs. .48, $p<.001$ ). Thus, the simple act of priming assessment of the Catalan government first has a significant polarizing effect. When primed this way, pro-independence people are more relatively trusting of the Catalan government, and pro-SQ people are more trusting of the Spanish government. However, pro-autonomy individuals are basically not affected by the treatment (.53 vs. .51, $p<.05)$; the confidence intervals between the control and treatment groups overlap with zero. For the proautonomy group, the relative trust in the governments 
is in between that of those with other territorial preferences and there is no main effect in the treatment (.60 vs. $.59, p=.27$ ). Figure 8 shows the plotted predicted probabilities from an OLS model controlling for the key sociodemographic variables (i.e., gender, education, employment status, household income, and Catalan origins). The figure shows that the pro-autonomy individuals' relative trust remains the same, whereas individuals with other territorial preferences are primed in opposite directions (see Supplementary File, Table G1, model 4 , for the full regression results, where the coefficient of interest is the interaction term between treatment assignment and territorial preference).

Overall, within the "control group," pro-independence individuals trust the Catalan government more than the Spanish government, but pro-autonomy and pro-SQ individuals' trust in the Catalan government is fairly equivalent to that of the Spanish government. However, pro-autonomy individuals are not susceptible to priming effects, whereas individuals on either policy extreme are. In the treatment group, relative trust in the Catalan government is larger for pro-independence individuals while it is smaller for pro-SQ individuals. The above suggests that pro-autonomy individuals may have more stable views on the different actors and outcomes relevant to the resolution of the conflict.

As a final piece of evidence (omitted due to space constraints), in the Supplementary File (Part H), we present additional descriptive findings on social networks that indicate why pro-autonomy individuals may be difficult to persuade (which could indicate one reason for the lack of susceptibility to trust priming). In the survey, we asked people to estimate the percentage of people in their network (relatives and friends) who supported independence. We find that pro-autonomy people are the most balanced subgroup regarding the composition of their social networks; most of such individuals report around $50 \%$ pro-independence individuals in their network. By contrast, the other two groups have more imbalanced networks, in that they have greater percentage of like-minded individuals in their networks. The role of social networks on territorial preferences should be further investigated, but we believe that this is consistent with evidence in this article and in other research suggesting a somewhat curbing role of pro-autonomy individuals in the context of political and social polarization around territorial issues (Balcells, Fernández-Albertos et al., 2021).

\section{Conclusion}

This article has shed light on a subgroup of individuals who, in a secessionist conflict, take intermediate positions between secessionist and pro-status quo views. We used individual-level evidence from the case of Catalonia, where a secessionist drive led by the Catalan government turned into an unprecedented institutional crisis in the fall of 2017. Using data from a two-wave online survey, we analyze the correlates of pro-autonomy views and consider different implications of these preferences regarding key government evaluations, vote choice, emotions, and trust of the Spanish and Catalan governments on a hypothetical agreement to resolve the conflict. The evidence overall suggests that there is a subgroup of individuals who have distinct views from those at the extremes of the territorial

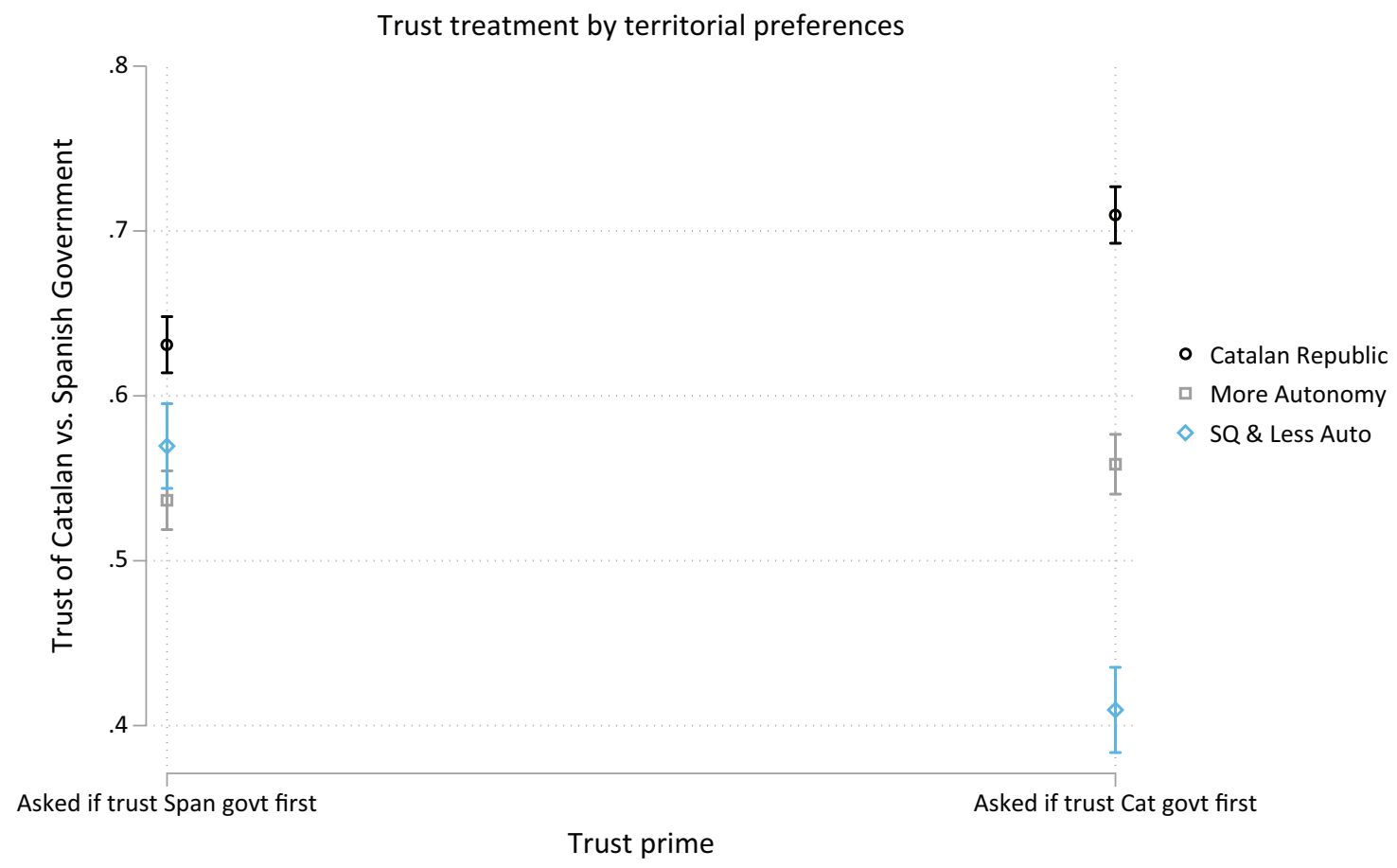

Figure 8. Trust prime experiment results, by territorial preferences. 
dimension, but we find limited evidence that standard socio-demographic factors explain this specific preference. There remains only a strong correlation between age and "intermediate" levels of Catalan (vs. Spanish) identity and preference for more autonomy.

Interestingly, the more autonomy group shares with the SQ \& less autonomy group some emotions around the conflict and some evaluations of the actions of the Catalan and Spanish governments during the secessionist crisis. This implies that, while this subgroup is probably more sympathetic to independence as a goal than to the SQ \& less autonomy (after all, they prefer more powers for the region), this constituency is probably hard to strongly persuade by secessionist actors. For example, pro-autonomy individuals did not feel comfortable around the declaration of independence and other unilateral secessionist actions; as argued above, they seemed to disagree with secessionists on the process more so than on the actual territorial outcomes they were trying to achieve. While they did not agree with some actions of Spanish state actors, more autonomy individuals seem closer in specific policy views to the pro$\mathrm{SQ} /$ less autonomy bloc than to the pro-independence one. Finally, pro-autonomy individuals seem to have less intense sentiments around political issues, be similarly trusting of both Catalan and Spanish governments with regards to a potential negotiated solution to the conflict, and be less affected by trust primes. Our evidence and findings hopefully justify further exploration of these individuals.

\section{Acknowledgments}

We thank José Fernández-Albertos, for helpful consultation and discussion, and Simón Ballesteros, Sara Fischer, and Benjamin Mishkin for research assistance. Three anonymous reviewers provided helpful feedback on the manuscript. This research has been funded by Duke University, the University of Oxford, and Georgetown University.

\section{Conflict of Interests}

The authors declare no conflict of interests.

\section{Conflict of Interests}

Supplementary material for this article is available online in the format provided by the author (unedited).

\section{References}

Amat, F., \& Balcells, L. (2021). Territorial conflict [Paper presentation]. The "Twisted Modernization" Workshop, Universitat de Barcelona.

Balcells, L. (2013). Mass schooling and Catalan nationalism. Nationalism and Ethnic Politics, 19(4), 467-486.

Balcells, L., Dorsey, S., \& Tellez, J. F. (2021). Repression and dissent in contemporary Catalonia. British Journal of Political Science, 51(4), 1742-1750

Balcells, L., Fernández-Albertos, J., \& Kuo, A. (2015). Preferences for inter-regional redistribution. Comparative Political Studies, 48(10), 1318-1351.

Balcells, L., Fernández-Albertos, J., \& Kuo, A. (2021). Secession and social polarization: Evidence from Catalonia (UNU-WIDER Working Paper 2021/2). World Institute for Development Economics Research.

Balcells, L., \& Villamil, F. (2020). The double-logic of internal purges: New evidence from Francoist Spain. Nationalism and Ethnic Politics, 26(3), 260-278.

Barceló, J. (2018). Batons and ballots: The effectiveness of state violence in fighting against Catalan separatism. Research \& Politics, 5(2), 469-481.

Beramendi, P. (2012). The political geography of inequality. Regions and redistribution. Cambridge University Press.

Bourne, A. K. (2014). Europeanization and secession: The cases of Catalonia and Scotland. Journal on Ethnopolitics and Minority Issues in Europe, 13(3), 94-120.

Brant, R. (1990). Assessing proportionality in the proportional odds model for ordinal logistic regression. Biometrics, 46, 1171-1178.

Centre d'Estudis d'Opinió. (2021). Inicio. Centre d'Estudis d'Opinió. https://ceo.gencat.cat/es/inici/index.html

Curtice, J. (2013). Who supports and opposes independence-And why? ScotCen Social Research. https:// www.scotcen.org.uk/media/176046/2012-whosupports-and-opposes-independence-and-why.pdf

Guibernau, M. (1999). Nations without states: Political communities in a global age. Polity Press.

Guibernau, M. (2006). National identity, devolution and secession in Canada, Britain and Spain. Nations and Nationalism, 12(1), 51-76.

Hechter, M. (2000). Containing nationalism. Oxford University Press.

Hierro, M. J., \& Gallego, A. (2018). Identities in between: Political conflict and ethnonational identities in multicultural states. Journal of Conflict Resolution, 62(7), 1314-1339.

Hierro, M. J., \& Queralt, D. (2021). The divide over independence: Explaining preferences for secession in an advanced open economy. American Journal of Political Science, 65(2), 422-442.

Horowitz, D. L. (1981). Patterns of ethnic separatism. Comparative Studies in Society and History, 23(2), 165-195.

Muñoz, J., \& Tormos, R. (2015). Economic expectations and support for secession in Catalonia: Between causality and rationalization. European Political Science Review, 7(2), 315-341.

Ormston, R. (2014). Minding the gap: Women's views of independence in 2014. ScotCen Social Research. https://www.scotcen.org.uk/media/563072/ssa2014-minding-the-gap-2.pdf

Pattie, C., Denver, D., Mitchell, J., \& Bochel, H. (1999). Partisanship, national identity and constitutional 
preferences: An exploration of voting in the Scottish devolution referendum of 1997. Electoral Studies, 18(3), 305-322.

Requejo, F., Garcia, J., Grau, M., Martín, G., Mora, H., \& Sanjaume, M. (2020). Democràcies liberals i protecció de l'autogovern. Com protegir les minories territorials de les decisions de la majoria [Liberal democracies and self-government protection. How to protect territorial minorities from majority decisions]. Institut d'Estudis de l'Autogovern.

Ricart-Huguet, J., \& Green, E. (2018). Taking it personally: The effect of ethnic attachment on preferences for regionalism. Studies in Comparative International Development, 53, 67-89.

Serrano, I. (2013). Just a matter of identity? Support for independence in Catalonia. Regional \& Federal Studies, 23(5), 523-545.

Sniderman, P., Hagendoorn, L., \& Prior, M. (2004). Predisposing factors and situational triggers: Exclusionary reactions to immigrant minorities. American Political Science Review, 98(1), 35-49.

Sorens, J. (2008). Regionalists against secession: The political economy of territory in advanced democracies. Nationalism and Ethnic Politics, 14(3), 325-360.

Watson, D., \& Clark, L. A. (1988). Development and validation of brief measures of positive and negative affect: The PANAS scales. Journal of Personality and Social Psychology, 54(6), 1063-1070.

YouGov. (2021). If there was a "two-stage" referendum on Scottish independence, how would you vote on the second question asking whether you would prefer independence, or greater powers for the Scottish Parliament? [Graph]. https://whatscotlandthinks.org/ questions/if-there-was-a-two-stage-referendumon-scottish-independence-how-would-you-voteon-the-second-question-asking-whether-youwould-prefer-independence-or-greater-powers-forthe-scottish-parliament

\section{About the Authors}

Laia Balcells is Provost's distinguished associate professor of government at Georgetown University. She is the author of Rivalry and Revenge: The Politics of Violence during Civil War (Cambridge University Press, 2017).

Alexander Kuo is an associate professor in the Department of Politics and International Relations, and tutorial fellow at Christ Church, University of Oxford. 